\title{
Cursos comerciais em colégio católico feminino: uma aparente contradição? Curitiba, 1940-1950*
}

\section{Trade courses in a female catholic school: apparent contradiction? Curitiba, 1940-50s}

\author{
Erica Piovam de Ulhôa Cintra ${ }^{1}$
}

\begin{abstract}
RESUMO
Curitiba, década de 1940. Os colégios católicos femininos da cidade ainda se organizavam para a fundação de escolas normais como oferta de ensino profissional em nível secundário às jovens mulheres da época. Nas décadas de 1940 e 1950, o magistério era o ponto alto para a formação da jovem mulher curitibana, especialmente no Instituto de Educação do Paraná (antiga Escola Normal). Mas "ser normalista" não seria a única opção às jovens mulheres daquela época. Em 1942 é fundado o Instituto Comercial São José (logo depois, Escola Técnica de Comércio São José, 1944), o primeiro projeto educativo de ensino profissional, em nível secundário, das Irmãs de São José no Paraná que já atuavam na área educacional - e não somente nessa área - na cidade e em outras localidades paranaenses. Nos anos 1940/1950 foi esse o único estabelecimento católico de ensino voltado à formação da jovem mulher em área técnica de comércio na cidade. Em todo o período estudado (1942-1955) quase 300 jovens mulheres foram formadas pela Escola para atuar no comércio como: auxiliares de escritório, contadoras e contabilistas (Técnico em Contabilidade). O presente artigo apresenta, em linhas gerais, alguns dos motivos que colaboraram para que

* O presente artigo é parte de minha dissertação de mestrado defendida no Programa de Pós-Graduação em Educação (história e historiografia da educação) da Universidade Federal do Paraná (UFPR). E a versão aqui parcialmente modificada foi apresentada na VI Jornada Nacional do HISTEDBR, realizada na Universidade Estadual de Ponta Grossa (UEPG), em 2005.

1. Mestre e Doutoranda em Educação (história e historiografia da educação) pela Universidade Federal do Paraná (UFPR). Bolsista CAPES. E-mail: piovam@onda.com.br.
\end{abstract}


as jovens mulheres realizassem seus estudos na área comercial e não no magistério, e como esse ensino geralmente conformado à formação masculina pode ser desenvolvido em um colégio católico feminino.

Palavras-chave: história da educação; educação feminina; ensino profissional; ensino comercial; educação católica.

\begin{abstract}
Curitiba, the 40s. Female catholic schools of the city were still organizing themselves in order to normal school foundation as an offer of professional teaching, in high school level, to women of the time. In the 1940s and 50 s, teaching was top to young women professional formation, mainly in Institute of Education of Paraná (ancient Normal School). But being "normalista" (i.e. undergraduate teacher) would not be the only alternative to women at the period. In 1942, São José Trade Institute (right after, São José Technical School, 1944) was founded. That was the first educative project of professional teaching, high school level, of the Sisters of São José in Paraná, who already developed activities in other Paraná localities. In the city, during the 1940/50s that was the only catholic education establishment for young women formation in technical area of trade. The School graduated almost 300 young women along the focused period (1942-1955), in order to work in commerce as office auxiliaries and accountants. The present work presents, not deeply, some motivations that worked to those young women develop their studies in trade area and not in teaching, and how such learning generally adapted to men could be developed in a female catholic school.

Keywords: education history; female education; professional education; trade education; catholic education.
\end{abstract}

Enquanto os colégios católicos femininos de Curitiba ainda se organizavam, na década de 1940, para a fundação das escolas normais, as Irmãs de São José (instaladas em Curitiba, desde 1896), iniciam os trabalhos educacionais com o Instituto Comercial São José (1942), depois Escola Técnica de Comércio São José (1944), destoando do conjunto dos colégios congêneres na cidade. E considerando que o magistério ou a escola normal representou, na década de 1940, especialmente em Curitiba, o ponto alto para a formação da jovem mulher (FUCKNER, 2000; IWAYA, 2001), que motivos teriam colaborado para que jovens mulheres realizassem o curso técnico comercial ofertado pela Escola? Teria sido a "expansão capitalista" da cidade e o desejo (ou necessidade) de exercer o trabalho que as mulheres começaram a invadir os espaços masculinos 
trocando as "femininas máquinas de costura pelas de escrever" (GANZ, 1994, p.111)? As possibilidades de resposta são aqui delineadas.

\section{Cursos comerciais: uma alternativa a educação profissional e secundária da época}

O Instituto Comercial São José foi fundado em 11 de novembro de 1942, em Curitiba, tendo por base o decreto-lei $n .^{\circ} 20.158$ que oficializou o ensino comercial no Brasil e regulamentou a profissão de Contador na reforma empreendida por Francisco Campos (1931). Logo depois, com a Lei Orgânica do Ensino Comercial (fins de 1943), que reorganizou esse ensino na reforma de Gustavo Capanema, mudanças se fizeram necessárias e o Instituto passou a denominarse Escola Técnica de Comércio São José (1944). Apesar das várias alterações que se processaram no cotidiano da escola, tais não comprometeram o projeto educativo de ensino profissional, em nível secundário, das Irmãs de São José no Paraná religiosas que já atuavam na área educacional - e não somente nessa área - na cidade e em outras localidades paranaenses. Nos anos 1940/1950 foi esse o único colégio católico feminino voltado à formação da jovem mulher em área técnica de comércio na cidade. Era a formação das jovens auxiliares de escritório, das contadoras e das contabilistas ${ }^{2}$.

A criação da Escola Técnica de Comércio São José pode ser traduzida como uma alternativa aos ensinos normal e secundário à época, em Curitiba. A formação de normalistas, inclusive, era difundida a módicas quadras e na mesma rua pela Escola Normal, hoje Instituto de Educação do Paraná Professor Erasmo Pilotto. Nas décadas de 1940 e 1950, esse estabelecimento público de ensino veio a ser o lócus da formação profissional feminina das jovens normalistas curitibanas (Cf.: IWAYA, 2001). Tanto que, em meados da década de 1950, Erasmo Pilotto, reconhecido educador paranaense, vai afirmar o "fato demais conhecido da exagerada e desnecessária concentração de professores na Capital" (PILOTTO, 1954, p. 72), no ano de 1946. Sinalizava aí a falta de professoras primárias nos municípios interioranos e a centralização das mesmas à capital paranaense. Por sua vez, os colégios católicos femininos, que até então investiam no ensino primário e no $1 .^{\circ}$ ciclo do ensino secundário, o ginásio, vão iniciar, nesse momento, além do $2 .^{\circ}$ ciclo do secundário (clássico e/ou científico), a difusão do ensino normal colaborando para ampliar ainda mais os quadros

2. A diferenciação entre "contadora" e "contabilista" visa distinguir as alunas egressas dos cursos de Contador (1945-1947) e de Técnico em Contabilidade (1947-1955) formadas pela Escola. 
professorais da cidade ${ }^{3}$.

Outro fator agravaria o quadro do ensino normal e do secundário na cidade: as limitações em relação ao mercado de trabalho aos egressos desses ensinos. No primeiro caso, como já indicado por Erasmo Pilotto, em processo de saturação como resultado da centralização das normalistas à capital do estado - e não raro normalistas constavam nos cursos comerciais da Escola ${ }^{4}$, e noutro, na não correspondência às expectativas dos setores produtivos da sociedade que reclamavam a participação de técnicos para o atendimento dos setores industrial e comercial. $\mathrm{O}$ ensino de nível secundário com caráter propedêutico estava muito longe dessa correspondência entre educação e trabalho. E o ensino profissional em nível secundário estava demasiadamente restrito a poucas instituições. Por exemplo, no ano de 1942, bem depois do fechamento do Instituto Comercial do Paraná (1905-1931, instituição pública) e conforme relata o Inspetor Federal da Divisão de Ensino Comercial no Estado do Paraná, Aryon Niepce da Silva, seriam os seguintes os destinos possíveis para os interessados em cursar o ensino comercial, do curso elementar ao superior, no Paraná, naquele ano:

3. As escolas normais fundadas eram as dos Colégios: Nossa Senhora de Lourdes (1946), Sagrado Coração de Jesus (1946), Sion (1949) e a do próprio São José (1955) - instituição que congregou, dentre outros níveis de ensino, os cursos comerciais da Escola Técnica de Comércio São José (FEDALTO, [1958?])

4. Em 1945, das 9 alunas matriculadas no $1 .^{\circ}$ ano do curso de contador, 2 apresentavam diploma de normalista; em 1946, das 12 alunas matriculadas no $1 .^{\circ}$ ano do curso de contabilidade, 5 eram normalistas (RELATÓRIO DO SERVIÇO DE ESTATÍSTICA DA EDUCAÇÃO E SAÚDE. Boletim de informações da ETCSJ ao M.E.S, referente ao ano de 1945. Curitiba, 1947; RELATÓRIO... referente ao ano de 1946. Curitiba, 1948). 


\section{Tabela 1: Acesso aos cursos do ensino comercial: Paraná, 1942}

\begin{tabular}{|c|c|c|c|}
\hline $\begin{array}{l}\text { Local e } \\
\text { cursos }\end{array}$ & $\begin{array}{l}\text { Propedêutico e } \\
\text { Contador }\end{array}$ & $\begin{array}{c}\text { Todos os cursos comer- } \\
\text { ciais* }\end{array}$ & $\begin{array}{l}\text { Curso superior de Admi- } \\
\text { nistração e Finanças ** }\end{array}$ \\
\hline Curitiba & & $\begin{array}{c}\text { Academia Parana- } \\
\text { ense de Comércio e } \\
\text { Faculdade de Ciências } \\
\text { Econômicas do Paraná } \\
\text { (depois, de Academia } \\
\text { para Escola Técnica de } \\
\text { Comércio ‘De Plácido e } \\
\text { Silva')*** }\end{array}$ & $\begin{array}{c}\text { Academia Paranaense de } \\
\text { Comércio e Faculdade } \\
\text { de Ciências Econômicas } \\
\text { do Paraná (mais tarde, } \\
\text { a Faculdade é integrali- } \\
\text { zada à Universidade do } \\
\text { Paraná) }\end{array}$ \\
\hline
\end{tabular}

Academia de Comércio anexa a Faculdade

Curitiba de Direito do Paraná (depois, Escola Técnica de Comércio anexa a Faculdade de Direito do Paraná)

\begin{tabular}{cccc}
\hline Curitiba & $\begin{array}{c}\text { Faculdade de Comér- } \\
\text { cio do Paraná (depois, } \\
\text { Escola Técnica de } \\
\text { Comércio Remington } \\
\text { do Paraná) }\end{array}$ & --- & -- \\
\hline Ponta & $\begin{array}{c}\text { Academia Pontagros- } \\
\text { sense de Comércio }\end{array}$ & --- & - \\
\hline
\end{tabular}

* Conforme o Decreto-Lei n. ${ }^{\circ} 20.158$, de 30 jun. 1931, o curso propedêutico (elementar) e os técnicos: secretário (1ano), guarda-livro (2), perito-contador (3), atuário (3), administrador-vendedor (3 anos).

** Único curso superior previsto em lei e apenas aos concluintes dos cursos: contador ou atuário. *** Após as alterações da Lei Orgânica do Ensino Comercial (1943).

Fonte: NIEPCE DA SILVA, 1942, p. 25.

A primeira constatação, ao observar a Tabela 1, é a de que se tratava de poucas instituições de ensino comercial para todo o estado do Paraná. As duas academias de comércio da capital, como eram chamadas as instituições de ensino comercial em face da regulamentação de 1931, estavam associadas às 'faculdades' - com conotação diferente de como hoje se entende essa instituição - e não todas, aparentemente, ligadas à especialidade dos cursos comerciais: a Academia de Comércio anexa a Faculdade de Direito do Paraná, parece ser esse exemplo, mas a aproximação justifica-se pelas várias disciplinas de caráter 
jurídico ${ }^{5}$. A outra academia de comércio da capital, a Academia Paranaense de Comércio e Faculdade de Ciências Econômicas, não contava com os "bacharelados" respectivos (Ciências Econômicas) que só viriam a acontecer após o ano de 1945. Antes, contava com todos os cursos comerciais técnicos, mais o propedêutico e o superior de Administração e Finanças - o único curso superior da área à época e da reforma de 1931. A Academia Pontagrossense de Comércio, em Ponta Grossa (PR), e a Faculdade de Comércio do Paraná, em Curitiba, contavam apenas com os cursos: propedêutico e contador - tal como logo iniciaria o Instituto Comercial São José. No entanto o que todas essas instituições teriam de surpreendente, diz respeito ao número geral de matrículas admitidas em seus cursos:

As matrículas crescem de ano para ano graças à confiança que a mocidade vem depositando nesses estabelecimentos, aliás se não completos na sua organização, pelo menos quasi completos, mas todos em perfeita harmonia com as instruções em face da legislação federal, apresentando no corrente ano letivo [1942] uma matrícula que se aproxima de 1.000 alunos (NIEPCE DA SILVA, p. 25).

O relato do Inspetor Federal da Divisão de Ensino Comercial do Estado informa o interesse da demanda pelo ensino comercial, a organização dos estabelecimentos desse ensino em face da legislação e o importante número de matrículas. Aproximando esse dado com outros disponíveis, pode-se confirmar um salto do número de matrículas nos cursos comerciais do Paraná. Em 1933, havia 6 instituições de ensino comercial no estado, possivelmente concentradas na capital ou em suas proximidades, com o registro de 174 matrículas ao todo (INSTITUTO NACIONAL DE ESTATÍSTICA, 1936, p. 322-330). Quase uma década depois, as instituições de ensino comercial de Curitiba e de Ponta Grossa (que significa "o todo" paranaense), embora em menor número, aproximam-se de 1.000 matrículas. Esse "salto" permite compreender um pouco mais a "confiança da mocidade" para tais cursos, que contabilizavam, entre um e outro dado, um acréscimo de mais de $570 \%$. Denota, especialmente, a correspondência aos interesses do sistema produtivo, e mesmo às expectativas

5. Para o curso técnico de contador, são elas: Noções de Direito Constitucional e Civil (1. ${ }^{\circ}$ ano), Legislação Fiscal (1. ${ }^{\circ}$ ano), Noções de Direito Comercial Terrestre (2. ${ }^{\circ}$ ano) e Prática do Processo Civil e Comercial (3. ${ }^{\circ}$ ano) (BRASIL. Decreto-lei $n .^{\circ} 20.158$ - 30 jun. 1931. Organiza o ensino comercial, regulamenta a profissão de Contador e dá outras providências. Diário Oficial do Distrito Federal, Rio de Janeiro, 9 jul. 1931). 
dessa demanda, para inclusão como força produtiva no mercado de trabalho. Havia assim uma emergência desses profissionais ante as exigências do próprio mercado de trabalho, especialmente nesse período, em face da urbanização e da industrialização vividos pelos pólos de desenvolvimento do Paraná (se não todos, a capital e Ponta Grossa) e que reclamavam a formação dessa demanda com alguma especialização para o trabalho, nesse caso para o comércio (Cf.: SINGER; MADEIRA, 1975).

O aumento do número de matrículas também estaria em consonância com as implementações do governo getulista e confere com a "dinâmica" de crescimento dos setores produtivos da sociedade e, assim, dos cursos profissionais de nível secundário entre os anos de 1930 e 1940 - e isso só tenderia a aumentar paulatinamente ${ }^{6}$. De certa forma, essa situação também confere importância à ação do ministro da pasta da educação e saúde, Francisco Campos, com a oficialização do ensino comercial e a regulamentação da profissão de contador, num momento em que seria mais compreensível a organização, não do ensino comercial, mas do industrial - o que faz posteriormente o ministro Gustavo Capanema com a expedição da primeira Lei Orgânica de Ensino, em 1942. A ação de Francisco Campos foi então decisiva para a difusão do ensino comercial no país, e mais precisamente para a capital do estado, nos anos posteriores a regulamentação de 1931 e até, pelo menos, a reorganização do ensino na reforma de 1943.

Ademais, esse salto ainda permite compreender e afirmar, no plano local, o que se passava no cenário nacional. O comércio, de modo geral, como setor produtivo, nos anos 1930/1940, estava em franco desenvolvimento e caminhava a par das transformações socioeconômicas que incrementavam e diversificavam o setor industrial do país. E, nesse período, não por mera coincidência, o ensino técnico comercial estava entre os mais difundidos ensinos profissionais de nível secundário em todo o país, notadamente para o público masculino. A década de 1930 foi o seu principal período de destaque o que muito colaborou a oficialização do ensino comercial ${ }^{7}$. Na década seguinte, a redefinição dos

6. Tal é a difusão de instituições de ensino comercial no país, em parte da década de 1940: 640 (1941), 721 (1942), 801 (1943), 955 (1944), 1.014 (1945), 1.123 (1946), 1.071 (1947) (IBGE, 1947 , p. 405,1950 , p. 397).

7. Considerando os dados do IBGE (Op. cit.) do período de 1932 a 1942, no interstício de quase uma década o ensino comercial manteve a liderança no número de unidades escolares de ensino profissional no país - com exceção dos anos de 1941 e 1942 quando o ensino doméstico obteve destaque sobre todos os ramos do ensino profissional (Cf.: CINTRA, 2005a, especialmente tabela 6, p. 51). A preponderância do ensino comercial em relação ao normal é mantida em tempo ainda posterior e pelo menos até o ano de 1947 (limite dos dados pesquisados). Em relação ao ensino industrial, a supremacia do ensino comercial finda em 1943 quando então esse assume a liderança dos números de escolas de ensino profissional no país. Seria coincidência essa última ocorrência no mesmo momento em que era aprovada e implementada a Lei Orgânica do Ensino Industrial? 
planos das instituições desse ensino no país ocorreu com a Lei Orgânica do Ensino Comercial (1943) mantida até às mudanças introduzidas pela Lei de Diretrizes e Bases da Educação Nacional n. ${ }^{\circ} 4.024$, em 1961. Assim, a criação do Ministério da Educação e Saúde (M.E.S.,1930) aliada as reformas educacionais estabelecidas por Francisco Campos e Gustavo Capanema nas décadas de 1930 e 1940, instituíram os aportes oficiais necessários para a sistematização do ensino profissional comercial no país e isso também para as décadas seguintes.

Então, considerando a centralização do ensino normal à capital do estado, o ensino secundário que não correspondia a formação para o trabalho, e o ensino comercial com expressivo aumento do número de matrículas e destaque no cenário nacional, em qual desses ensinos o investimento educacional poderia se fazer mais interessante e promissor àquela época? No caso das Irmãs de São José, em Curitiba, a opção foi pela diversificação do ensino profissional feminino. A constituição do Instituto Comercial São José, por um lado, garantiria à sua demanda uma abreviada entrada no mercado de trabalho com certa especialização e, por outro, essa diversificação do ensino se constituiria também em eficaz estratégia de participação da instituição no mercado educacional àquele período. Somava-se, portanto, às instituições que realizavam a correspondência entre educação e trabalho sem, contudo, abrir mão dos interesses da própria instituição de ensino: católica e feminina.

\section{Elementos de enunciação de um ensino de profusão: novo prédio escolar, corpo docente especializado, profissionalização de jovens mulheres}

Para oferecer essa modalidade de ensino para o público feminino nos primeiros anos da década de 1940, as Irmãs de São José contaram com a cooperação de importante personalidade da vida pública e conhecedor da área e do ensino comercial, o próprio inspetor federal da Divisão de Ensino Comercial no Estado do Paraná: Aryon Niepce da Silva. Com sua experiência profissional e pedagógica, Niepce da Silva contribuiria sobremaneira para qualquer assunto relacionado ao ensino dessa especialidade, bem como, aos que se referissem à "perfeita harmonia" com a legislação federal - recuperando suas palavras anteriormente. Também contribuiria para o início dos trabalhos educacionais da instituição, outro inspetor federal do ensino comercial que assumiu função em 1943: Carlos Sternberg Valle.

Nos diferentes documentos escolares a respeito da memória da instituição 
(históricos da escola), Niepce da Silva e Sternberg Valle ladeiam a insistente menção à participação das "famílias curitibanas" e de autoridades locais para a realização de um ensino adaptado à realidade da capital paranaense. Adaptação essa que precisaria assumir ainda contornos mais visíveis para fazer vislumbrar um lugar mais representativo para o projeto educativo que as Irmãs de São José organizavam, portanto, um novo prédio escolar.

FIGURA 1 - Aspecto do edifício escolar

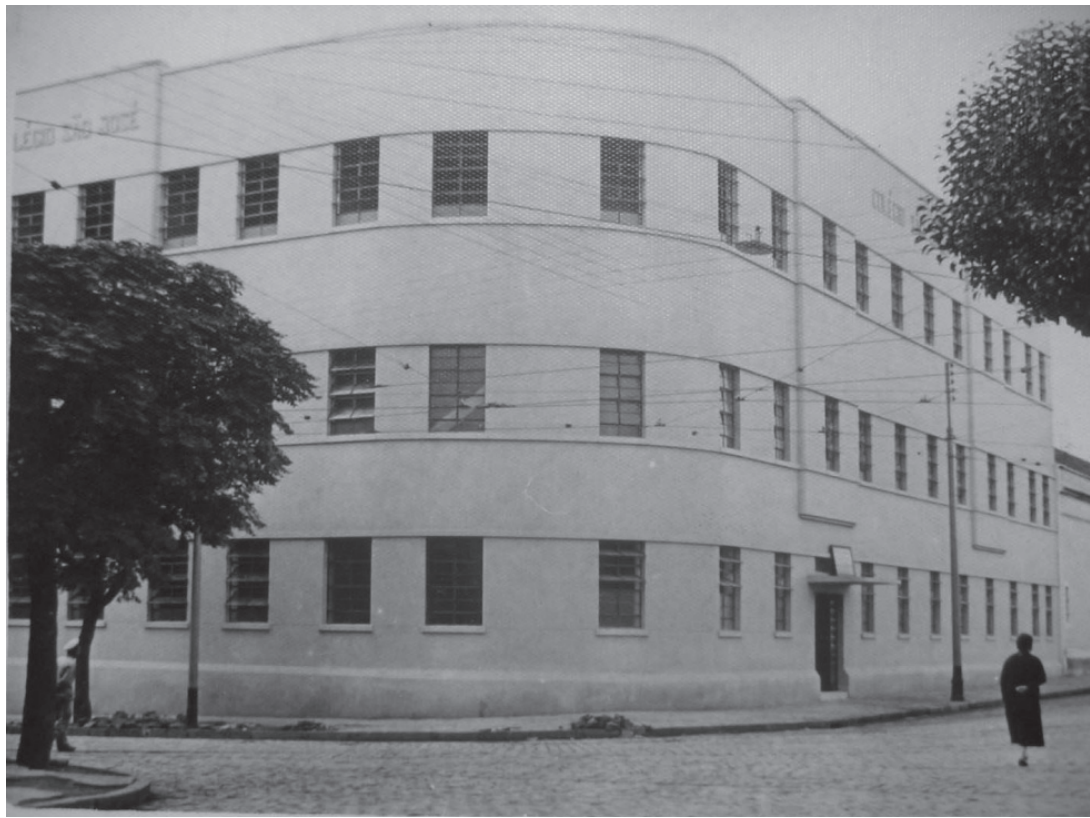

Um guarda (esq.) e uma senhora (dir.) observam o novo prédio escolar, entre as esquinas das ruas centrais da cidade. À extrema direita, parte da edificação anterior. Curitiba, 1942. Fonte: Arquivo Colégio São José, Curitiba.

Nessa empreitada as Irmãs investem na organização do complexo escolar situado em plena região central da cidade entre duas vias principais, a Emiliano Perneta e a atual 24 de Maio, e uma praça, a Rui Barbosa, com visibilidade para as três faces do edifício escolar. Tal é o empreendimento para o período que o mesmo só será totalmente concluído no início da década seguinte ao da construção da primeira parte (1942). Tanto o lugar de edificação quanto o próprio prédio escolar, estrategicamente posicionado no local em que lhe permite o terreno, entre as vias centrais e não à margem do núcleo urbano, são portadores de uma intencionalidade pedagógica: de projeção e de influência 
sobre a sociedade, a capital do estado, em que o edifício torna-se "dotado de uma inteligência invisível" (VIÑAO FRAGO; ESCOLANO, 1998, p. 33). E, por traduzir o projeto educativo intentado, o de lugar de formação de mulheres para o trabalho técnico, neste sentido, alcança a representatividade e a altura esperada na conformação de um novo espaço escolar. A obra, capturada pelas lentes do fotógrafo (Figura 1), ainda nos últimos detalhes do acabamento, não deixa dúvida de que se trata de um prédio escolar: "Colégio São José”, em ambas as faces no alto destacado das mesmas. É para ele que duas pessoas, enquadradas na composição da imagem, voltam os seus olhares: uma senhora (uma irmã?), e um guarda. E com que sentido se põem a observar o feito, como se fizessem reverência, eretos e com as mãos unidas atrás do corpo.

A planta arquitetônica de 1942, assinada pelo engenheiro civil Ildefonso Clemente Puppi, um dos primeiros professores do Instituto Comercial São José e reconhecido educador do cenário paranaense, apresenta alguns detalhes da ocupação do terreno: o pavimento térreo com as instalações administrativas, o laboratório, os gabinetes, os museus e as salas de aula; o primeiro pavimento/ andar, a sala de professores, a biblioteca, a sala de estudos e a Capela; o segundo pavimento, destinado a Congregação; e a preservação de uma área central no terreno, destinada ao pátio não coberto. A arquitetura escolar é mencionada em alguns documentos como de característica da "pedagogia moderna" sobressaindo, nos relatos da memória histórica do Colégio, a construção de um prédio amplo e de estrutura sólida, iluminado, arejado, "de acordo com as posturas municipais" para que assim bem atendesse ao propósito educacional. Preocupação esta muito afeiçoada às questões da higiene e que atingiria não apenas os infantes e as jovens, mas todos os participantes daquele cenário escolar.

De um lado, a edificação corresponderia aos anseios da cidade na construção de uma imagem, para a capital paranaense, diferente daquela acanhada dantes. A cidade "rumo ao progresso" é anunciada no início da década de 1940 com o Plano Agache, e culminada com os festejos do Centenário de Emancipação do Paraná, no ano de 1953. Nesse interstício era preciso distanciar a urbe daquela imagem provinciana, de cidade interiorana, aproximando-a dos "ares de cidade grande" para o que muito contribuiu a realização de várias obras como a Biblioteca Pública, o Teatro Guaíra, entre outros. Por outro lado, essa "pedagogia moderna" cunhada ao prédio escolar pode ser resultante da transposição do que viria a ocorrer no interior da escola. Depois do prédio pronto, haveria toda uma organização do aparato pedagógico com a ordenação dos espaços internos, a composição do mobiliário escolar (Figura 2), a variedade de recursos e materiais didáticos e paradidáticos que apinhariam as diferentes salas ou gabinetes das disciplinas escolares, etc. Todos elementos caros a "nova pedagogia" que demonstravam acolher e que auxiliaria na normatização dos 
participantes àquele cotidiano escolar que se preparava e definia os "saberes a ensinar" e as "condutas a inculcar". (JULIA, 2001, p. 10).

Essa interpretação pode ter alcançado o seu exterior para confirmar a edificação do prédio escolar como um elemento dessa "nova" organização pedagógica, em instrumentos e práticas, para a educação profissional de mulheres - mas quem disse que o "novo" representa polaridade acentuada com o "velho"? Nisto, não se pode deixar de observar o aspecto de enclausuramento que evoca a materialidade do "novo" prédio escolar. O prédio sólido, modesto nos ornamentos, de organização completamente voltada para o interior, mantém o mesmo aspecto da edificação anterior (1941): a fachada rente a rua como fronteira com o exterior (VIÑAO FRAGO; ESCOLANO, 1998, p. 89-99). Tal aspecto ressalta, inclusive, a ausência de um elemento prestigiado pelas edificações escolares modernas: a proeminente e convidativa escadaria. Inexistente na atual construção, a ausência desse elemento de transição marca a entrada abrupta no interior do Colégio: uma pequena entrada na face principal é a passagem da rua para a escola. Será que haveria alguém para a acolhida ou mesmo para a observação das alunas ao entrar? O que fariam? Como reagiriam às mais expansivas nessa "passagem"? Por sua vez, o contato com o "mundo externo" é feito apenas quando dos episódicos eventos planejados: visitas a instituições, desfiles cívicos e religiosos, etc. Aqui, no mínimo, são dois projetos em mudança e que coexistem para fundar esse sentido de "pedagogia moderna" da escola católica, do seu prédio escolar e de seus instrumentos didáticos, e que não, exatamente, sejam excludentes entre si. Então têm-se aí, o projeto de uma cidade em mudança (macro) e o de uma pedagogia em mudança (micro) que se amalgamaram no projeto educativo das Irmãs de São José em Curitiba. 
FIGURA 2 - Aspecto da entrada principal do prédio escolar

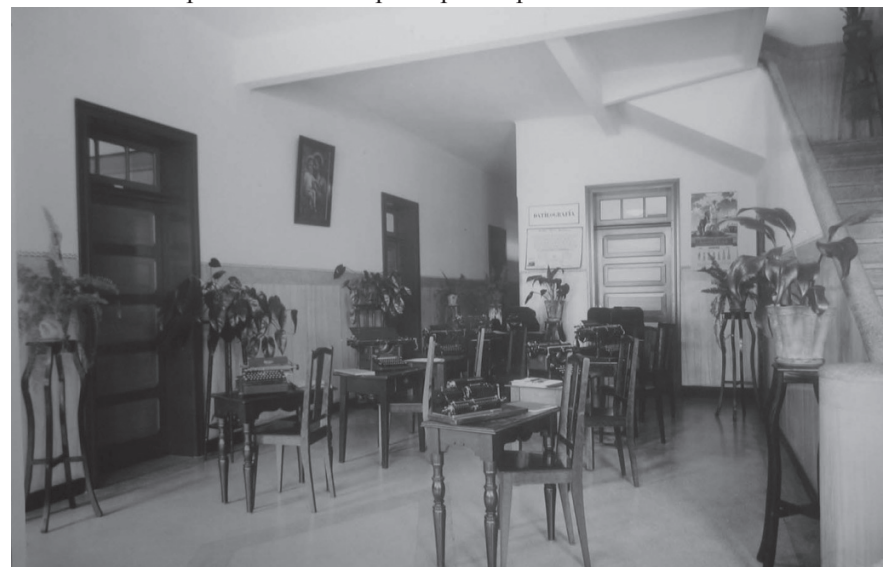

Ênfase à Datilografia no hall de entrada do Instituto Comercial São José, 1942. Foto: Kabza Curityba.

Fonte: Arquivo do Colégio São José, Curitiba.

E para dar conta desse projeto educativo de profusão, as religiosas, com registro de professoras no Departamento Nacional de Educação, assumiram todas as disciplinas do curso que formavam as auxiliares de escritório: o curso comercial básico (reforma de 1943). Já o corpo docente do $1 .^{\circ}$ ano do curso de Contador, em 1943, as religiosas não seriam maioria participando apenas nas disciplinas de Estenografia e de Mecanografia. Para as demais disciplinas do $1 .^{\circ}$ ano do curso de Contador, compunham o corpo docente, majoritariamente masculino, professores com registros na Divisão do Ensino Comercial do M.E.S. que atuavam em outras instituições de ensino inclusive nas faculdades da capital paranaense ${ }^{8}$. Interessante observar a respeito que, sendo esse um colégio católico

8. Eram eles: Aryon Niepce da Silva (disciplina Direito Constitucional e Civil), diplomado em Direito, acumulava a função de professor da Faculdade de Filosofia, Ciências e Letras do Paraná e do Colégio Estadual do Paraná (autor do livro O ensino comercial no Brasil, publicado em 1942); João Batista Zagonel Passos (Legislação Fiscal), diplomado em Direito e em GuardaLivros, lecionava no Colégio Sagrado Coração de Jesus; Ildefonso Clemente Puppi (Matemática Comercial), formado em Engenharia Civil, lecionava na Faculdade de Engenharia do Paraná e nos Colégios Nossa Senhora de Lourdes e Estadual do Paraná; Lourival Portella Natel (Contabilidade), diplomado Contador pela Academia de Comércio anexa à Faculdade de Direito do Paraná e funcionário público do Banco Nacional de Comércio, em Curitiba. Outros nomes foram se somando no decorrer da trajetória da escola, inclusive mulheres. Desde 1945, Gisela Portugal, diplomada Contadora, lecionava as disciplinas de: Contabilidade Geral e Merceologia, para os cursos técnicos, e Escrituração Mercantil, Prática de Escritório e Caligrafia, para o curso comercial básico da Escola Técnica de Comércio São José (Relatórios de Verificação da Escola Técnica de Comércio São José, 1943 a 1946, Curitiba). 
feminino, como seria a relação entre as alunas e um quadro docente masculino e vice-versa? Devia ser uma relação interessante para os professores esse contato com o "universo feminino", as alunas, as religiosas administradoras da Casa e as religiosas professoras. E, ainda, certamente acostumados ao ensino dos "homens de negócios" ensinariam ali eles às "mulheres de negócios". Será que faziam adaptações do conteúdo e de suas estratégias de ensino para lidar com as classes femininas? O que deixariam de trazer do "universo masculino", dos estudos das classes masculinas para as femininas? Tantas perguntas...

$\mathrm{E}$ a esse respeito, o depoimento de Victória, aluna da turma iniciada em 1943, não dá margens a outras interpretações (Cf.: CINTRA, 2005, p. 215-225; 280-281). A ação educativa dos professores é afirmada de modo seguro. Eram "bons professores", e ainda: "muito sérios". Essa afirmação reforçada da ação correta dos professores sugere também uma ação moralizadora e estritamente voltada a função de ensinar e com "o giz e o talento", diz ela. Mas se o depoimento de Victória permite compreender pouco àquelas questões, colabora, sobretudo, para visualizar outro aspecto da educação feminina nos anos 1940: a necessidade da jovem mulher estudar e ter um diploma, "um cheque em branco" ela diz, para o caso de precisarem trabalhar. Às jovens mulheres daquele período era necessário então um comprovante ou pode-se dizer um "bilhete de passagem" que assegurasse às moças a entrada no mundo do trabalho e exigiria delas uma qualificação. E Victória encarna essa necessidade com grande seriedade já que realiza, ao mesmo tempo, dois cursos de ensino profissional: o de normalista (na Escola Normal) e o de contadora, seus dois "cheques" da década de 1940.

\section{Na trajetória da instituição escolar, "cursos avulsos" e de datilografia. Por que não os comerciais?}

O Instituto Comercial São José é originado quatro décadas após as Irmãs de São José terem iniciado, em Curitiba, o atendimento educacional com o ensino primário no Externato São José (1902). Até a década de 1940, os cursos ali ministrados, além do primário e do jardim de infância, eram aulas de piano, de bordado e, note, de datilografia - curso esse de origem remota frente aos investimentos que seriam realizados a partir da década de 1940 com os cursos comerciais. A ocorrência da oferta desse curso como extracurricular em uma instituição que contava apenas com cursos de formação como hoje se chama, de educação infantil e de séries iniciais, é significativa. Certamente, o curso de datilografia, não se referia à formação das crianças, mas sim às jovens curiti- 
banas e, dentre elas, àquelas que ensejassem uma entrada breve no mercado de trabalho, em escritórios, casas comerciais, bancos, etc. O curso de datilografia era para essas jovens mulheres. De caráter prático e de curta duração, o curso possibilitava ao seu término um certificado com o qual conferia a capacitação das concluintes para a ocupação de atividades ligadas a prestação desse serviço na cidade. Era o primeiro passo para o alcance de "algo mais" na formação dessas mulheres: por que não uma profissionalização mais acurada ante a emergência industrial e comercial da época? Por que não os cursos comerciais... O curso de datilografia poderia ser essa chamada para a realização das atividades comerciais da escola, ao menos, como uma qualificação em área já conhecida do trato educacional das religiosas (diz-se desse curso).

Não menos importante é o destaque para as outras atividades "comuns" ao sexo feminino ofertadas, nesse caso, também como "cursos avulsos", extracurriculares. O piano, o bordado e também o corte e costura, eram eles próprios os cursos extracurriculares - algo que muito destoa da composição dos currículos de cursos voltados à educação feminina cujos conhecimentos são considerados essenciais para a preparação das jovens ao casamento e à maternidade (Cf.: PILLA, 1999; FUCKNER, 2000). Essa diferenciação nos currículos escolares femininos, feita nesse caso, permite refletir sobre um outro lado desses conhecimentos. Além da formação de "boas moças", prendadas, dedicadas ao lar, entretidas no espaço doméstico, por outro lado, podem ter conferido, especialmente às mulheres de classe média, outro sentido agregado àquele: o de uma possibilidade elementar de renda. Assim, com o aprendizado desses conhecimentos com outra finalidade que não somente a pretendida na formação de "boas moças", esses conhecimentos e atividades de que as jovens se apropriaram, de maneira voluntária ou não, ganham aí outro sentido. $\mathrm{O}$ piano, para as musicistas, poderia até alegrar as tardes dos chás das amigas de casa, mas quiçá de alguma casa de chá! O bordar e o coser, da mesma forma, dado o talento das mesmas, poderia ir além dos remendos e dos cuidados com as vestes familiares.

Isto permite inferir que, por trás do ensino dessas refinadas atividades na formação das mulheres, estava presente também o propósito de instruí-las em atividades que as possibilitassem adentrar em alguma fronteira do mercado de trabalho. E, em vista do curso de datilografia, em especial, havia o propósito mesmo da formação dessas mulheres para o trabalho. E a existência desse curso (datilografia) na instituição situa o envolvimento das Irmãs com a formação de mulheres para o trabalho em outros projetos formativos do Colégio anteriores mesmo ao Instituto Comercial São José. O trabalho, a profissionalização, era um dos focos essenciais na formação dessas jovens mulheres, na sua maioria advindas da classe média. E o ensino comercial era a opção. Mas essa escolha 
aventaria alguma contradição?

Um curso comercial em colégio católico feminino, aparentemente, pouco se encaixaria na perspectiva de uma formação feminina voltada para o espaço doméstico, por outro lado, encaixa-se perfeitamente ante as mudanças provocadas pela expansão industrial e comercial vivenciadas pelo país e pela cidade, naquele período em que despontava a diversidade de atividades produtivas desempenhadas por mulheres, e não só nas instâncias da educação e da saúde (Cf.: GANZ, 1994). O espaço fabril, por exemplo, foi um dos espaços em que as mulheres, especialmente as mais pobres, se fizeram muito presentes, inclusive assumindo atividades consideradas masculinas como na metalurgia (MOURA, 1989; RAGO, 2001); e o setor de serviços (escritórios, comércio ou serviços públicos), significou, em meados do XX, a possibilidade real de inserção das mulheres, sobretudo da classe média, no trabalho remunerado (LAGRAVE, 1991; BASSANEZI, 1996). Diante disso, o setor educacional se adaptaria a nova realidade produtiva dos setores econômicos da sociedade. E assim à candidata citadina aos cursos de nível secundário, seriam ofertados, além do ensino secundário, os cursos de ensino profissional: normal, comercial e doméstico.

Com tantas mudanças, a Igreja Católica não tardaria em reconhecê-las e acompanhá-las a seu modo na formação da juventude tal qual houvera feito anteriormente com a investida - não só na cidade, mas em todo o país - das congregações religiosas e depois a difusão dos colégios católicos. Mas nesse caso, do ensino comercial, age na cidade isoladamente. É apenas uma congregação religiosa (Irmãs de São José) que assume o ensino profissional feminino em área marcadamente masculina: o comércio - muito embora essa formação não prescindisse dos aspectos considerados "propriamente femininos". O alcance da ciência, da técnica e as transformações da vida em sociedade era algo para os quais os colégios católicos femininos teriam que voltar cada vez mais sua atenção, sem, contudo, abstê-los da religiosidade e da formação moral católica. Afinal, os "novos tempos" assim o exigiam. 


\section{Considerações finais}

Durante longo tempo, os colégios católicos femininos instalados no país dedicaram-se ao atendimento da demanda constituída por filhas da elite do local de sua instalação e a profissionalização da mulher era componente dispensado na formação dessas jovens. Por outro lado, a profissionalização era algo que interessava especialmente às filhas das demais camadas sociais, mais pobres, sem grandes possibilidades de casamento com "um bom partido". Passado algum tempo, a perspectiva da profissionalização de jovens mulheres entra na pauta de um colégio católico das Irmãs de São José, em Curitiba. Em meados dos anos 1940, o trabalho no comércio em casas comerciais, nos bancos, nos escritórios, ou como autônomas na área contábil, ou ainda como professoras do ensino comercial, era uma realidade para as primeiras egressas da Escola Técnica de Comércio São José (instituição extinta em 1988). A constituição dessa escola é resultante da articulação de um momento histórico, nacional e local, específico, e na conjugação de projetos educacionais que pretenderam responder as demandas da época: o das mudanças estruturais da economia brasileira, o das mudanças culturais em relação a presença da mulher no trabalho (e nos trabalhos considerados masculinos), o das políticas públicas em educação e para o ensino profissional nas décadas de 1930/1940, e mesmo o da estratégia política e afirmativa da Igreja Católica. Perspectivas que permearam a existência dessa escola, bem como permitem pensar as motivações que pesaram na escolha das jovens mulheres (ou de suas famílias) por esse ensino diferenciado. E essa ação, inclusive, não seria pioneira nessa congregação religiosa que já contava, pelo menos, com a Escola de Comércio de Santos (SP). No Paraná, as Irmãs de São José, no decorrer da década de 1940, além de constituírem a Escola Técnica de Comércio São José em Curitiba (PR), fundaram também: uma Escola de Comércio, em Castro (PR), e a Escola de Comércio Aparecida, em Rio Caçador (SC). Neste sentido, o ensino comercial pode ser considerado uma especialidade educacional das Irmãs de São José no Brasil. 


\section{REFERÊNCIAS}

BASSANEZI, C. Virando as páginas, revendo as mulheres: Revistas femininas e relações homem-mulher, 1945-1964. Rio de Janeiro: Civilização Brasileira, 1996.

CINTRA, E. P. de U. Ensino profissional feminino em Curitiba: a Escola Técnica de Comércio São José (1942-1955). Dissertação (Mestrado em Educação) - Programa de Pós-Graduação em Educação da Universidade Federal do Paraná, Curitiba, 2005a.

. Cursos comerciais em colégio católico feminino: uma aparente contradição? Curitiba, 1940 - 1950. In: JORNADA NACIONAL DO HISTEDBR, 6, 2005, Ponta Grossa. Anais... Ponta Grossa: UEPG, 2005. 1 CD-ROM.

FUCKNER, C. M. Magistério e Casamento: memória e formação no Colégio de Educação Familiar do Paraná (1953-1986). Dissertação (Mestrado em Educação) - Programa de Pós-Graduação em Educação da Universidade Federal do Paraná, Curitiba, 2000.

GANZ, A. M. Vivências e falas: trabalho feminino em Curitiba, 1925-1945. Dissertação (Mestrado em História) - Setor de Ciências Humanas Letras e Artes da Universidade Federal do Paraná, Curitiba, 1994.

IWAYA, M. Palácio da Instrução: representações sobre o Instituto de Educação do Paraná Professor Erasmo Pilotto (1940-1960). Dissertação (Mestrado em Educação) - Programa de Pós-Graduação em Educação da Universidade Federal do Paraná, Curitiba, 2001.

JULIA, D. A cultura escolar como objeto histórico. Revista Brasileira de História da Educação, Campinas, n. 1, p. 9-43, jan./jun. 2001.

LAGRAVE, R.-M. Uma emancipação sob tutela. Educação e trabalho das mulheres no século XX. In: DUBY, G.; PERROT, M. (Dir.). História das Mulheres no Ocidente. v. 5. Porto: Afrontamento, p. 505-543, 1991.

MOURA, E. B. B. de. Além da Indústria Têxtil: o trabalho feminino em atividades 'masculinas'. Revista Brasileira de História, São Paulo, Marco Zero, v. 9, n. 18, p. 83-98, ago. 1989.

PILLA, M. C. B. A. Escola de virtudes: sociabilidades no Colégio Cajuru, 1907-1942. Dissertação (Mestrado em História) - Setor de Ciências Humanas Letras e Artes da Universidade Federal do Paraná, Curitiba, 1999.

RAGO, M. Trabalho feminino e Sexualidade. In: DEL PRIORE, M. (Org.). História das Mulheres no Brasil. São Paulo: Contexto, 2001, p. 578-606. 
SINGER, P.; MADEIRA, F. Estrutura do emprego e trabalho feminino no Brasil: 1920-1970. Caderno 13. São Paulo: Brasiliense, 1975.

VIÑAO FRAGO, A.; ESCOLANO, A. Currículo, espaço e subjetividade: a arquitetura como programa. Rio de Janeiro: DP\&A, 1998.

\section{FONTES}

BRASIL. Decreto-Lei n. ${ }^{\circ} 6.141$ - 28 dez. 1943. Lei Orgânica do Ensino Comercial. Diário Oficial do Distrito Federal, Rio de Janeiro, 31 dez. 1943.

. Decreto-lei $n^{\circ} 20.158$ - 30 jun. 1931. Organiza o ensino comercial, regulamenta a profissão de Contador e dá outras providências. Diário Oficial do Distrito Federal, Rio de Janeiro, 9 jul. 1931.

FEDALTO, P. A arquidiocese de Curitiba na sua história. Curitiba, (1958?).

INSTITUTO BRASILEIRO DE GEOGRAFIA E ESTATÍSTICA. Anuário Estatístico do Brasil, Ano 8, 1947, p. 405. . Anuário Estatístico do Brasil, Ano 11, 1950, p. 397.

INSTITUTO NACIONAL DE ESTATÍSTICA. Anuário Estatístico do Brasil, Ano 2. Rio de Janeiro: Tip. do Departamento de Estatística e Publicidade, 1936.

NIEPCE DA SILVA, A. O ensino comercial no Brasil: história, legislação, jurisprudência da Divisão do Ensino Comercial. Curitiba: Ed. Guayra, 1942.

PILOTTO, E. A educação no Paraná. Síntese sobre o ensino público elementar e médio. Rio de Janeiro: MEC/INEP, CILEME, 1954.

RELATÓRIO DO SERVIÇO DE ESTATÍSTICA DA EDUCAÇÃO E SAÚDE. Boletim de informações da ETCSJ ao M.E.S, referente ao ano de 1945. Curitiba, 1947.

. Boletim de informações da ETCSJ ao M.E.S, referente ao ano de 1946. Curitiba, 1948.

Relatórios de Verificação da Escola Técnica de Comércio São José, 1943 a 1946, Curitiba.

Fotografias do Arquivo do Colégio São José, Curitiba. 